\title{
Diet, physical activity and sedentary behaviour in 11-13 year old UK adolescents: The Gateshead Millennium Study
}

\author{
L. Basterfield ${ }^{1}$, J. K. Reilly ${ }^{1}$, E. L. Slack ${ }^{1}$, K. N. Parkinson ${ }^{1}$, M. S. Pearce ${ }^{2}$, A. Dale ${ }^{3}$, \\ A. S. Le Couteur ${ }^{2}$, A. J. Adamson ${ }^{1}$ and J. J. Reilly ${ }^{4}$ \\ ${ }^{1}$ Institute of Health \& Society, Human Nutrition Research Centre, Newcastle University, Newcastle upon Tyne NE2 4HH, \\ ${ }^{2}$ Institute of Health \& Society, Newcastle University, Sir James Spence Institute, Royal Victoria Infirmary, Newcastle upon \\ Tyne NE1 4LP, ${ }^{3}$ Queen Elizabeth Hospital, Gateshead NE9 6S and ${ }^{4}$ Physical Activity for Health Research Group, \\ School of Psychological Sciences and Health, University of Strathclyde, Glasgow G1 1XU, UK
}

Obesity remains a global public health challenge. Recent survey data suggest that $33.9 \%$ of English 10-11 year old children are overweight or obese $^{(1)}$, and do not meet recommendations for physical activity ${ }^{(2)}$ (60 minutes moderate-to-vigorous intensity physical activity (MVPA) daily ${ }^{(3)}$ or aspects of dietary intake ${ }^{(4)}$ (5 portions of fruit and vegetables daily). The purpose of the current study was to measure prevalence of overweight and obesity in adolescents, and describe their dietary intake, physical activity (PA) and sedentary behaviour (SB) in relation to UK health recommendations.

Cross-sectional analysis of the Gateshead Millennium Study (GMS), a longitudinal birth cohort recruited in 1999/2000 in northeast England ${ }^{(5)}$. Height and weight were measured and body mass index (BMI) and BMI z score derived ${ }^{(6)}$. Dietary intake was measured on two occasions using an age-appropriate, computerised, self-completion 24 -hr recall (SCRAN24) ${ }^{(7)}$. Nutritional output is generated automatically from the associated database. PA and SB were objectively measured over seven days using Actigraph GT1M accelerometers to provide overall PA (mean accelerometer counts per minute (cpm)), time spent in MVPA and time spent in sedentary behaviours (SB). All data were collected in 2012.

Of 530 children taking part, complete data were available for 374 (48\% male). Mean age of the participants was 12.5 years. BMI (19.8) and BMI z score (0.60) were similar in males and females, $66(17.6 \%)$ were overweight, and $74(19.8 \%)$ were obese. Mean time spent in MVPA was 22 min.d ${ }^{-1}$, with just 14 adolescents (3.7\%) averaging $60 \mathrm{~min} \cdot \mathrm{d}^{-1}$ (12 male 2 females). Males were significantly more active than females for all variables, and females spent more time in sedentary behaviours than males $(87.5 \%$ v. $85.3 \% P<0.001)$. Females consumed significantly less energy than males $(P<0.001)$ and less energy from fat $(P=0.001)$, but $\%$ energy from fat was similar at approx. $31 \%$ energy. Mean intake of fruit and vegetables was 1.3 portions, with only $23(6.1 \%)$ of the sample achieving 5 a day, $68(18.2 \%)$ consumed no fruits or vegetables over the 2 days recorded.

In this sample of secondary school adolescents, public health guidelines for physical activity and diet were not met, and levels of overweight and obesity were high. The challenge to increase adherence to public health guidelines to improve adolescent health remains.

This work was funded by Gateshead Primary Care Trust, University of Strathclyde and Breathe North.

1. The Health and Social Care Information Centre (2012) National Child Measurement Programme: England, $2011 / 2012$ school year.

2. Health Survey for England 2008 (2009) Volume 1: Physical activity and fitness.

3. Chief Medical Officers of England Scotland Wales and Northern Ireland (2011) Start active, stay active: a report on physical activity from the four home countries' Chief Medical Officers. London: Department of Health.

4. Department of Health (2011) National Diet and Nutrition Survey. Headline results from Years 1 and 2 (combined) of the Rolling Programme (2008/ 2009-2009/2010). London: HMSO.

5. Parkinson KN, Pearce MS, Dale A et al. (2010) Cohort Profile: The Gateshead Millennium Study. Int J Epidemiol 40, $308-317$.

6. Cole T, Freeman J, Preece M (1995) Body mass index reference curves for the UK, 1990. Arch Dis Child 73, 25-29.

7. Foster E, Hawkins A, Delve J et al. (2013) Reducing the cost of dietary assessment: Self-Completed Recall and Analysis of Nutrition for use with children (SCRAN24). J Hum Nutr Diet In Press. 